\title{
Author Correction to: Pooled Analyses of Phase III Studies of ADS-5102 (Amantadine) Extended-Release Capsules for Dyskinesia in Parkinson's Disease
}

\author{
Lawrence W. Elmer ${ }^{1}$ Jorge L. Juncos ${ }^{2}$ - Carlos Singer ${ }^{3}$ - Daniel D. Truong ${ }^{4}$. \\ Susan R. Criswell ${ }^{5} \cdot$ Sotirios Parashos $^{6} \cdot$ Larissa Felt $^{7} \cdot$ Reed Johnson $^{7}$ \\ Rajiv Patni ${ }^{7}$
}

Published online: 10 April 2018

(C) Springer International Publishing AG, part of Springer Nature 2018

\section{Author Correction to: CNS Drugs https://doi.org/10.1007/s40263-018-0498-4}

An Online First version of this article was made available online at http://link.springer.com/journal/40263/ onlineFirst/page/1 on 12 March 2018. An error was subsequently identified in the article, and the following correction should be noted:
Table 2, Primary efficacy results for the phase III studies and pooled populations at week 12: in the 'Pooled' section of the table, the 'Placebo' and 'ADS-5102' column headings are transposed. The corrected table is shown in the following page.

The original article has been corrected.

The original article can be found online at https://doi.org/10.1007/ s40263-018-0498-4.

Lawrence W. Elmer

Lawrence.Elmer@utoledo.edu

1 Department of Neurology, University of Toledo College of Medicine, 3120 Glendale Avenue, Toledo, OH 43614, USA

2 Department of Neurology and Movement Disorders, Emory University School of Medicine, Atlanta, GA, USA

3 Department of Neurology, University of Miami, Miami, FL, USA

4 The Parkinson's and Movement Disorder Institute, Fountain Valley, CA, USA

5 Department of Neurology, Washington University, St. Louis, MO, USA

6 Struthers Parkinson's Center, Golden Valley, MN, USA

7 Adamas Pharmaceuticals, Inc., Emeryville, CA, USA 


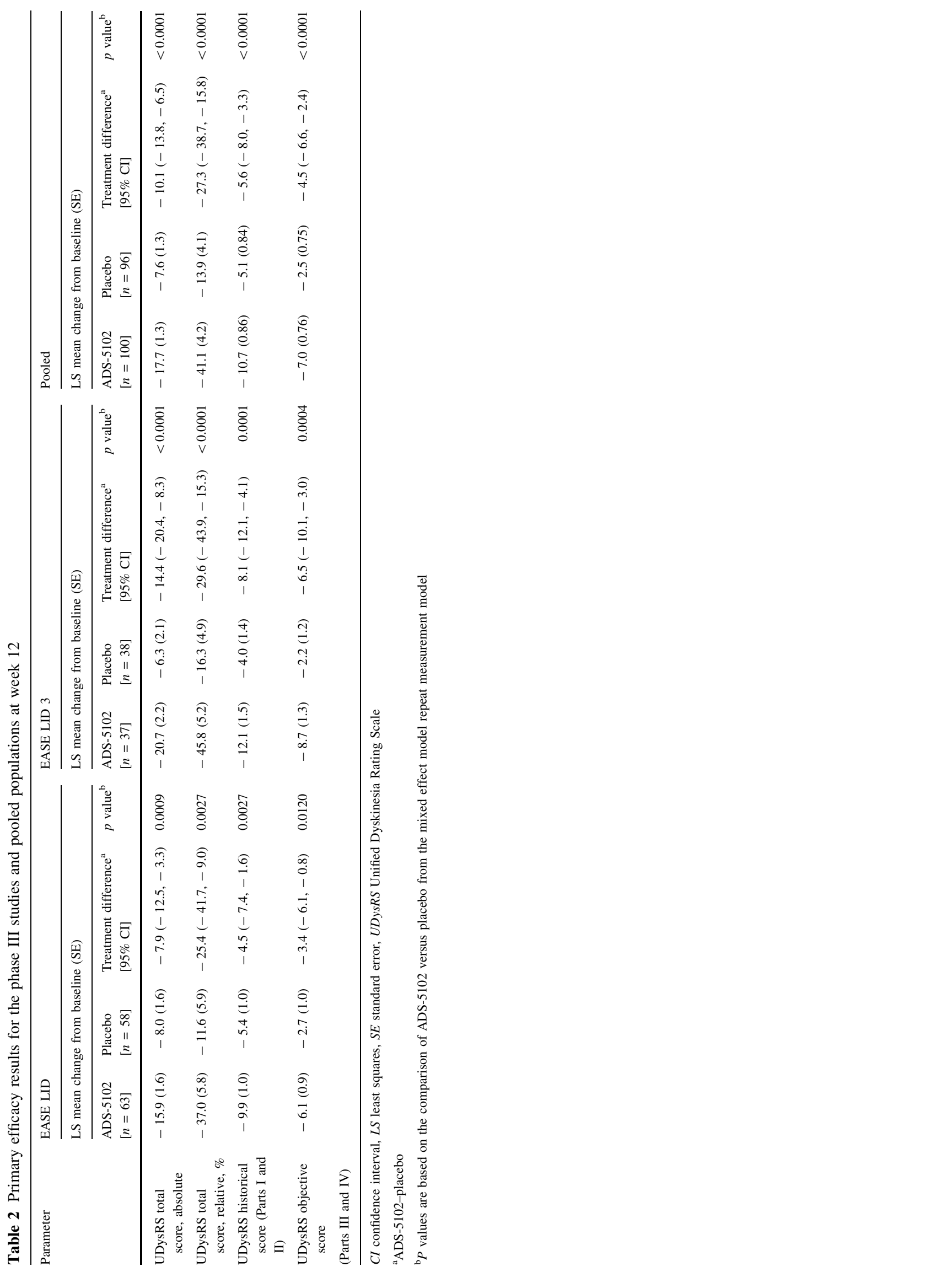

